\title{
Determination of the relative configuration of tropinone and granatanone aldols by using TBDMS ethers
}

\author{
Ryszard Lazny ${ }^{* 1}$, Aneta Nodzewska ${ }^{1}$, Katarzyna Sidorowicz ${ }^{1}$ \\ and Przemyslaw Kalicki ${ }^{2}$
}

\section{Full Research Paper}

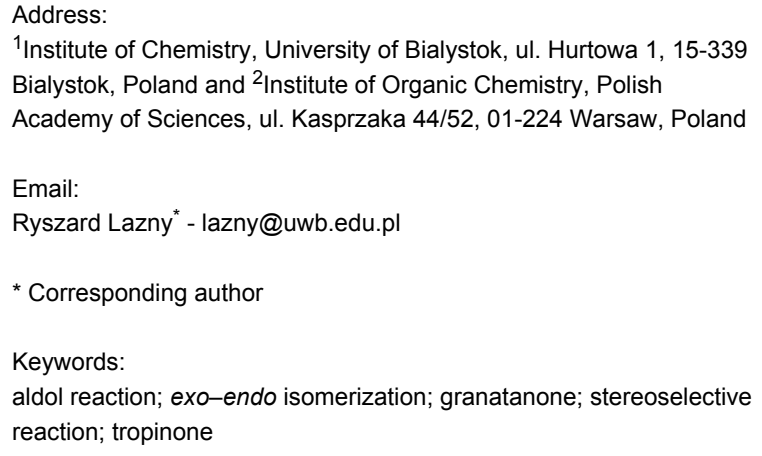

${ }^{1}$ Institute of Chemistry, University of Bialystok, ul. Hurtowa 1, 15-339 Bialystok, Poland and ${ }^{2}$ Institute of Organic Chemistry, Polish Academy of Sciences, ul. Kasprzaka 44/52, 01-224 Warsaw, Poland

Email:

Ryszard Lazny* - lazny@uwb.edu.pl

* Corresponding author

Keywords:

aldol reaction; exo-endo isomerization; granatanone; stereoselective reaction; tropinone

\author{
Beilstein J. Org. Chem. 2012, 8, 1877-1883. \\ doi:10.3762/bjoc.8.216 \\ Received: 24 July 2012 \\ Accepted: 02 October 2012 \\ Published: 02 November 2012 \\ Associate Editor: M. S. Sherburn \\ (C) 2012 Lazny et al; licensee Beilstein-Institut. \\ License and terms: see end of document.
}

\begin{abstract}
The relative configurations of tert-butyldimethylsilyl (TBDMS) ethers of all four diastereomers of the aldols of tropinone (8-methyl-8-azabicyclo[3.2.1] octan-3-one), as well as of granatanone (9-methyl-9-azabicyclo[3.3.1]nonan-3-one), were determined from NMR data, and from the observed interconversion of the diastereomers (exo,anti to endo,syn and exo,syn to endo,anti). The exo forms invert to endo isomers in the presence of silica gel. The relative configuration of a new isomer of tropinone aldol accessible synthetically through the direct solventless reaction of tropinone and benzaldehyde in the presence of water was determined as exo,syn by comparison of NMR data of the aldol isomers, in particular vicinal coupling constants and shifts corresponding to the side-chain $\mathrm{CH}$ group, with data of related TBDMS derivatives and confirmed by single-crystal X-ray diffraction.
\end{abstract}

\section{Introduction}

Enantiomerically pure, and racemic, diastereomerically pure aldols of tropinone have been used as key intermediates in stereoselective syntheses of natural tropane alkaloids and their analogues [1], including the unnatural enantiomer of cocaine (ent-cocaine) [2], knightinol [3], alkaloid KD-B [3] and ferrugine [4,5]. Stereoselective syntheses of nortropinone aldols $[6,7]$ and N-protected nortropinone aldols $[5,8,9]$, which can open access to other N-substituted analogues, have also been described. The known diastereomerically and enantiomerically pure aldols of tropinone (8-methyl-8-azabicyclo[3.2.1]octan-3one) and granatanone (9-methyl-9-azabicyclo[3.3.1]nonan-3one) (Figure 1) were synthesized by enantioselective deprotonation with lithium amide bases followed by diastereoselective aldol reaction with aldehydes [10,11]. In all the aldol reactions 
Me

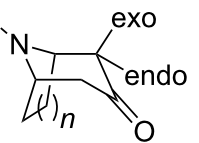

1, tropinone, $n=1$

2 , granatanone, $n=2$

Figure 1: The exo and the endo substituents at the $\alpha$-carbon (C-2 by tropane numbering) of the tropinone or granatanone scaffold shown in two alternative projections.

promoted by achiral (LDA $[5,12]$ ) or by chiral lithium amides (e.g., lithium bis(1-phenylethyl)amide [4,5] or Koga's amide [3]), including amides immobilized on a polymeric carrier $[13,14]$, the major products had the exo,anti configuration (Scheme 1).

Configuration of the exo,anti-3 was assigned based on X-ray diffraction [15]. Granatanone aldols, including $N$-benzyl derivatives, obtained with lithium amides were identified as the exo,anti isomers based on X-ray crystallography $[16,17]$. Granatanone aldols with exo,syn configuration have been observed only as minor products [17]. Until recently other isomers and synthetic procedures for their preparation remained unknown. We succeeded in preparing other isomers through an unexpected direct reaction of the ketones with aromatic aldehydes in the presence of catalytic amounts of water (Scheme 1) [18-20]. In our preliminary synthetic report the major isomeric products accessible under these conditions were assigned the exo,syn configuration. DFT calculations suggest that selectivity in the solventless reaction results from equilibration and the higher stability of the $\mathrm{O}-\mathrm{H} \cdots \mathrm{N}$-hydrogen-bond-stabilized conformer of the exo,syn isomer [20,21].

Herein, we wish to report a method used for identification of the relative configuration of this new isomer of the tropinone aldol and closely related granatanone aldol. To the best of our knowledge, all diastereoisomers of tropinone and granatanone aldols synthesized to date have the exo configuration. The other possible isomers, i.e., the endo forms, have never been isolated or described. Their appearance in some experiments has been mentioned [22]. We have made an effort to devise a way to identify these elusive endo isomers.

In this paper, we propose a simple method for the fast identification of all of the diastereomers of tropinone and granatanone aldols, including the endo isomers, through their silyl ether derivatives.

\section{Results and Discussion}

The new aldol product of the solventless reaction of tropinone with benzaldehyde had relative stereochemistry different from the exo,anti configuration, as judged from its NMR spectra. In particular the chemical shift and coupling constant of the characteristic carbinol $\mathrm{CH}$ signal differed from the known exo,anti isomer. Coupling constants of both isomers $(3.1 \mathrm{~Hz}$ for exo, anti and $2.6 \mathrm{~Hz}$ for the new product) were similar. Usually the vicinal coupling constants for syn and anti isomers differ enough to allow for configuration assignment [23] (e.g., aldols of cyclic ketones such as piperidone and cyclohexanone fall within the following typical ranges: syn: ca. $2-3 \mathrm{~Hz}$, anti: ca. 7-9 Hz).

In principle the new product could have had any of the three remaining possible configurations. However, we suspected that the unknown isomer was likely the exo,syn-aldol (i.e., the other exo product formed by stereoelectronically and sterically favored axial attack) [24] or the endo,syn isomer (resulting from the exo-endo inversion of the known exo,anti-3, Scheme 2).

The question of whether the exo isomer could invert to the endo form was answered by attempted isomerization (Scheme 2) under various conditions (basic, acidic, imidazole, silica gel in various solvents). The exo, anti aldols showed only decomposition to tropinone and benzaldehyde or elimination to benzylidene derivatives. The behavior of the new isomer under the same isomerization conditions was similar and gave no indications regarding its stereochemical form. It appeared that in this case (as it was for the exo,anti isomer [3]) attempts to convert the presumed exo isomers to the expectedly more thermodynamically stable endo isomers would be also fruitless, unless the hydroxy group was protected (e.g., by silyl ether). In light of

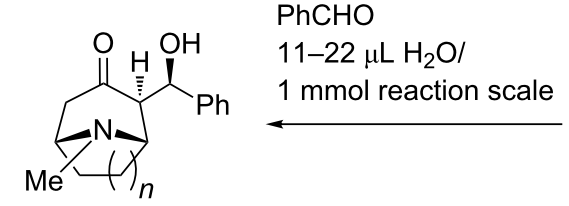

exo, syn-3, $n=1$

exo, syn-4, $n=2$

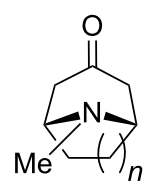

1, tropinone, $n=1$

2, granatanone, $n=2$

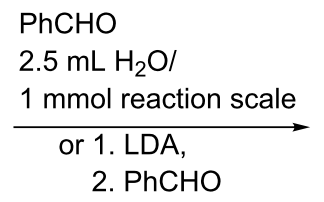

2. $\mathrm{PhCHO}$

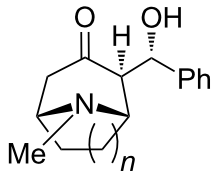

exo, anti-3, $n=1$

exo, anti-4, $n=2$

Scheme 1: Typical preparation of representative tropinone and granatanone aldols $[3,17,20]$. 


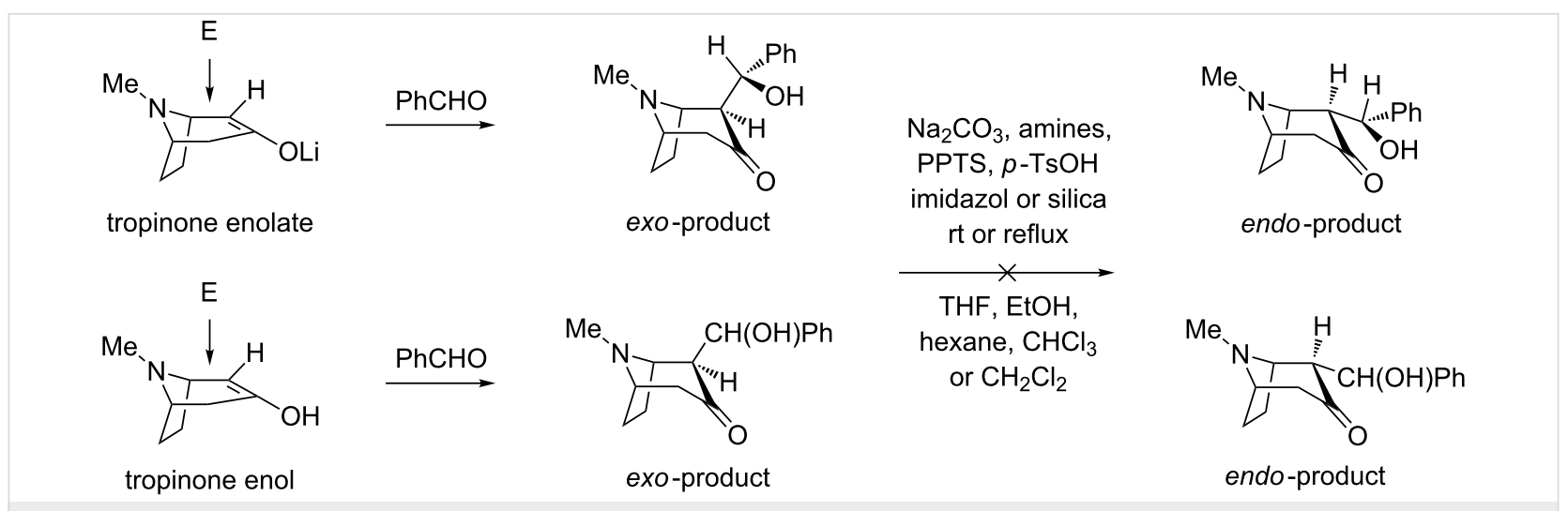

Scheme 2: Sterically and stereoelectronically favored trajectory for the approaching electrophile (E) and attempted inversions of configuration of the known and unknown tropinone aldol isomers.

the sensitive nature of the aldols we reasoned that making a stable derivative was necessary.

The TBDMS ethers of aldols have been already used for exo-endo isomerization of tropinone aldols [3]. Blocking of the hydroxy group with an ether or ester group would make formation of internal hydrogen bonding to the amine nitrogen or the carbonyl oxygen H-bond acceptors impossible, thus changing significantly the structure of aldols in aprotic solvents used for NMR. $N$-Benzyl analogues of the granatanone [16] and tropinone [9] aldols as well as aldols of granatanone [17] showed in crystalline form an intramolecular hydrogen bonding involving the free hydroxy group. We expected that such a change, reflected in the chemical shift and couplings, could be useful for discerning relative configurations. The aldol of unknown configuration was converted into silyl ether by reaction with tert-butyldimethylsilyl chloride (TBDMSCl) in the presence of DMAP and triethylamine (Scheme 3).

Because TBDMS ethers 5 with exo, anti and endo,syn configuration, as well as a method for their conversion, has been described [3], we expected that through comparison of ${ }^{1} \mathrm{H}$ NMR

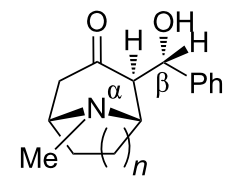

exo, anti-3, $n=1$, $\alpha-\mathrm{CH}: 2.43 \mathrm{ppm}$

exo, anti-4, $n=2$,

$\beta-\mathrm{CH}: 5.27 \mathrm{ppm}, \mathrm{d}, J=3.6 \mathrm{~Hz}$

$\alpha-\mathrm{CH}: 2.57$ ppm

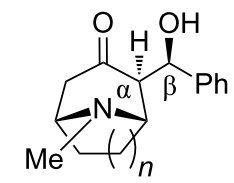

exo, syn-3, $n=1$,

$\beta-\mathrm{CH}: 5.01 \mathrm{ppm}, \mathrm{d}, J=2.6 \mathrm{~Hz}$

$\alpha-\mathrm{CH}: 2.38 \mathrm{ppm}$

exo, syn-4, $n=2$, $\beta-\mathrm{CH}: 5.08 \mathrm{ppm}, \mathrm{d}, J=2.0 \mathrm{~Hz}$ $\alpha-\mathrm{CH}: 2.48$ ppm
$\beta-\mathrm{CH}: 5.23 \mathrm{ppm}, \mathrm{d}, J=3.1 \mathrm{~Hz}$

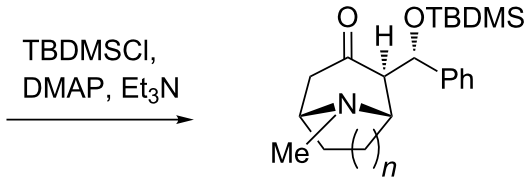

exo, anti-5, $n=1$, $\beta-\mathrm{CH}: 5.28 \mathrm{ppm}, \mathrm{d}, J=9.6 \mathrm{~Hz}$ $\alpha-\mathrm{CH}: 2.35 \mathrm{ppm}$

exo, anti-6, $n=2$,

$\beta-\mathrm{CH}: 5.21 \mathrm{ppm}, \mathrm{d}, J=9.3 \mathrm{~Hz}$ $\alpha-\mathrm{CH}: 2.45$ ppm

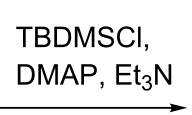

Scheme 3: Preparation of TBDMS derivatives of all diastereomers of tropinone and granatanone aldols (included are characteristic NMR data for the side-chain $\beta-\mathrm{CH}$ protons and shifts of the axial or equatorial $\alpha-\mathrm{CH}$ protons (at $\mathrm{C}-2)$ ).

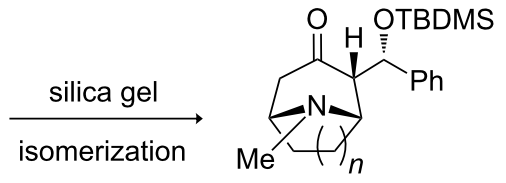

endo, syn-5, $n=1$, $\beta-\mathrm{CH}: 5.10 \mathrm{ppm}, \mathrm{d}, \mathrm{J}=7.3 \mathrm{~Hz}$ $\alpha-\mathrm{CH}: 3.00$ ppm

endo, syn-6, $n=2$,

$\beta-\mathrm{CH}: 5.26 \mathrm{ppm}, \mathrm{d}, J=6.8 \mathrm{~Hz}$ $\alpha-\mathrm{CH}: 2.97 \mathrm{ppm}$

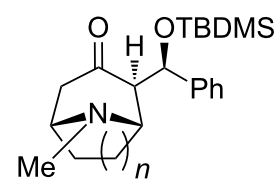

exo, syn-5, $n=1$,

$\beta-\mathrm{CH}: 5.24 \mathrm{ppm}, \mathrm{d}, J=9.3 \mathrm{~Hz}$ $\alpha-\mathrm{CH}: 2.45 \mathrm{ppm}$

exo, syn-6, $n=2$, $\beta-\mathrm{CH}: 5.16 \mathrm{ppm}, \mathrm{d}, J=8.6 \mathrm{~Hz}$ $\alpha-\mathrm{CH}: 2.54$ ppm

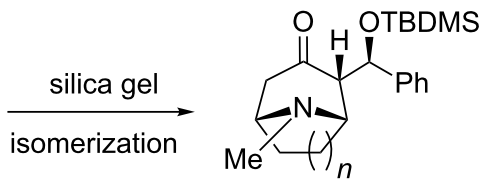

endo, anti-5, $n=1$ $\beta-\mathrm{CH}: 5.01 \mathrm{ppm}, \mathrm{d}, J=7.6 \mathrm{~Hz}$ $\alpha-\mathrm{CH}: 3.06$ ppm

endo, anti-6, $n=2$, $\beta-\mathrm{CH}: 5.01 \mathrm{ppm}, \mathrm{d}, J=8.7 \mathrm{~Hz}$ $\alpha-\mathrm{CH}: 3.14$ ppm 
data we would be able to exclude or confirm the structure of the new aldol TBDMS ether as endo,syn. The TBDMS derivative was different from the known endo,syn-isomer 5. Thus the new aldol was either the exo,syn or the endo,anti isomer. Inducing isomerization of the unknown aldol TBDMS ether to the typically more stable endo form could be an indication pointing to the exo,syn configuration. From the tested methods for isomerization, the most suitable turned out to be the absorption on a silica column combined with separation. Although the silyl ether of the new isomer of tropinone aldol isomerised in the presence of silica, giving the last of the four isomeric TBDMS derivatives, in a similar way as described for the exo,anti-5, its conversion was noticeable faster than for the exo,anti-5. At this point it was clear that the new aldol isomer must have had the exo,syn configuration. Isomerization of its TBDMS derivative was so facile that its chromatographic purification was hardly possible. This agreed with expectations based on intuitive van der Waals radii and conformational analysis. Inspection of molecular models indicates that the pseudoaxial substituent of the syn isomer should experience more steric congestion on the tropinone bicyclic skeleton with equatorial $N$-methyl [9], than the same group of the anti configuration. It was interesting to see if one could obtain the free aldols in the endo forms by TBDMS deprotection. Under the typical desilylation conditions (1 M TBAF in THF) no formation of aldols, but rather products of their decomposition were detected in the resulting complex reaction mixtures. The presence of a relatively acidic pseudoaxial hydrogen atom at the $\alpha$-carbon to carbonyl (C-2) is likely responsible for the facile elimination of a water molecule and formation of an isomeric mixture of condensation products $((E)$ and $(Z)$-2-benzylidene tropinones) in analogy to the known elimination of acetic acid from the acetyl derivative of the aldol [3].

More conclusive indication came from comparison of the characteristic signals (doublets) of the side-chain $\mathrm{CH}$ groups (sidechain $\beta$-carbon to the carbonyl group, Scheme 3). The fact that ${ }^{1} \mathrm{H}$ NMR signals of exo,syn-5 differed markedly from the endo,syn-5 (as compared on the same NMR instrument) but were similar to the exo,anti-5 supported the tentative assignment further. Knowing that in tropinone the axial $\alpha$-protons are deshielded versus the equatorial protons by ca. $0.5 \mathrm{ppm}[12,25]$, we were also able to identify positively, within the pairs of interconverting isomeric TBDMS ethers, the isomer with exo and endo side chain (equatorial and axial $\alpha-\mathrm{CH}$, respectively). On the basis of the observed exo-endo isomerization, and trends in NMR data changes upon isomerization, we were fairly certain of the assigned stereochemistry of the new isomer as exo,syn-3. This procedure developed on tropinone aldols was reproduced on corresponding granatanone aldols, providing TBDMS ethers of all four possible diastereomers of $\mathbf{6}$ (Scheme 3) and identifying the major product of the solventless reaction of granatanone with benzaldehyde $[20,21]$ as exo,syn-4.

The vicinal coupling constants characteristic for the aldols and the TBDMS ethers (Scheme 3) can provide some insight into the preferred conformations in solution. Using the familiar Karplus correlation of the vicinal $J$ and the dihedral angle [2628 ], we suggest the preferred conformations shown in Figure 2. The aldol conformations shown could likely be stabilized by formation of an internal H-bond to the amine nitrogen as observed in crystals.

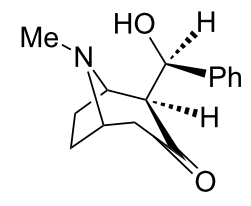

exo, anti-3

$50^{\circ}$ with $\mathrm{H}$-bond

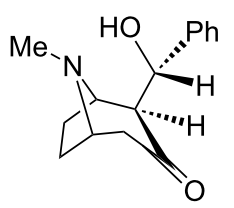

exo, syn-3 $55^{\circ}$ or $110^{\circ}$ with $\mathrm{H}$-bond

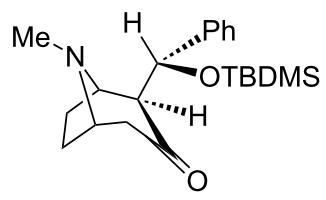

exo, anti- 5

$170^{\circ}$

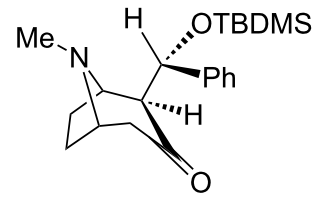

exo, syn- 5 $160^{\circ}$

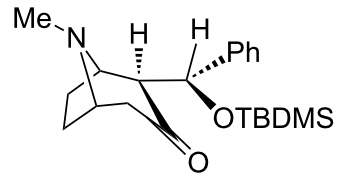

endo, syn-5 $135^{\circ}$

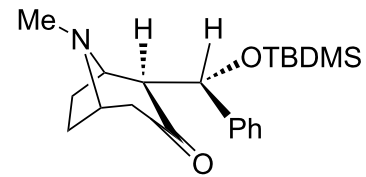

endo, anti- 5 $10^{\circ}$

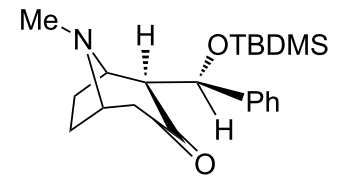

endo, syn- 5

$18^{\circ}$

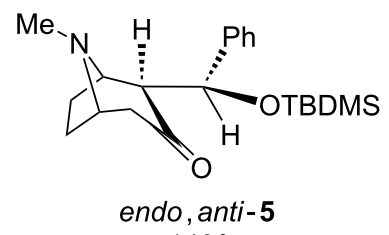

$140^{\circ}$

Figure 2: Approximate representations of likely conformations of tropinone aldols and their TBDMS ethers in solution, having dihedral $\mathrm{H}-\alpha \mathrm{C}-\beta \mathrm{C}-\mathrm{H}$ angles accounting for the observed vicinal couplings. 
The dihedral angle in the structure exo,anti-3 is estimated, based on $J=3.1 \mathrm{~Hz}$, to be ca. $50^{\circ}$ and for exo,syn-3 slightly more than $55^{\circ}$ or $110^{\circ}$, based on $J=2.6 \mathrm{~Hz}$. The alternative conformations, without a possible $\mathrm{H}$-bond to nitrogen for exo,anti-3, and an angle of ca. $110-115^{\circ}$ corresponding to $J=3.1 \mathrm{~Hz}$ would have significant steric strain. In both TBDMS derivatives exo,anti-5 and exo,syn-5 the estimated dihedral angle of $160-170^{\circ}$ corresponds to reasonable conformations. In the endo forms 5 the angle determined as $18^{\circ}$ or $135^{\circ}$ for endo,syn-5 and $10^{\circ}$ or $140^{\circ}$ for endo,anti-5 can be found in two of the shown alternative arrangements. The analysis for tropinone aldols is representative also for the granatanone analogues $\mathbf{4}$ and $\mathbf{6}$.

After identifying the exo,syn configuration by the described procedure we succeeded in preparing the crystalline form of the new isomer of $\mathbf{3}$ suitable for single crystal diffraction. Meticulous purification by precipitation with hexane, followed by slow crystallization from ether gave suitable crystals of the isomer, configuration of which was unambiguously determined as exo,syn (Figure 3) by X-ray diffraction.

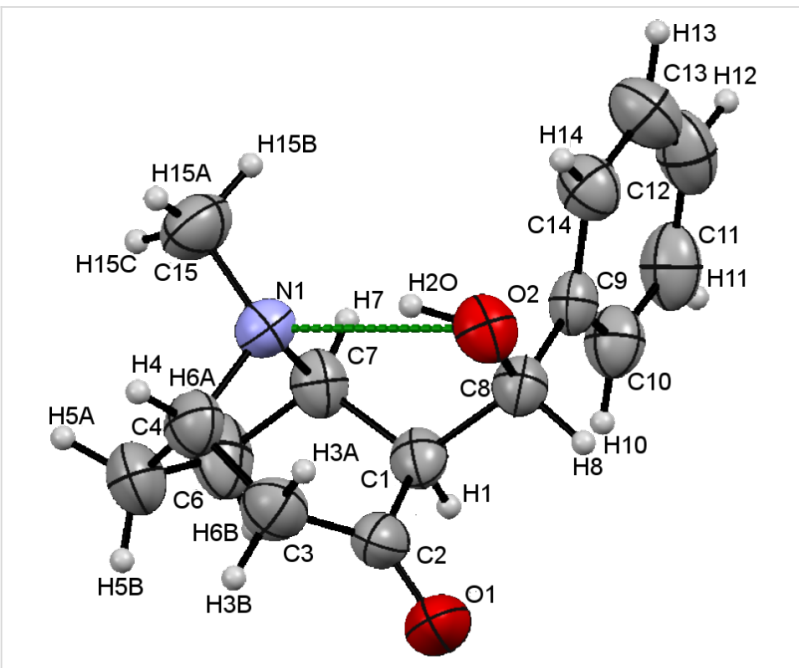

Figure 3: X-ray structure of aldol exo,syn-3 synthesized by direct, solventless reaction of tropinone with benzaldehyde in the presence of catalytic amounts of water, showing an intramolecular $\mathrm{H}$-bond: $\mathrm{N} 1 \cdots \mathrm{O} 2$ 2.763(2), $\mathrm{N} 1 \cdots \mathrm{H} 1.920(2) \AA, \mathrm{N} 1 \cdots \mathrm{H} 2 \mathrm{O} \cdots \mathrm{O} 2$ angle $151(2)^{\circ}$. Displacement ellipsoids are drawn at $30 \%$ probability level; atom numbering is arbitrary.

Atoms $\mathrm{H} 1$ and $\mathrm{H} 8$ were found in syn relation to each other, while the 1'-hydroxybenzyl group at $\mathrm{C} 1$ is on the exo side of the bicyclic tropane scaffold pointing towards the C4-N1-C7 bridge (pseudoaxial on the tropinone six-membered ring). The crystal structure is also characterized by internal hydrogen bonding between the nitrogen $\mathrm{N} 1$ and the oxygen $\mathrm{O} 2$ atom (N1-H2O-O2). The configuration of a related granatanone aldol ( $p-\mathrm{NO}_{2}-\mathrm{PhCHO}$ derived [20]) was also confirmed by $\mathrm{X}$-ray analysis as exo,syn with analogous hydrogen bonding [17].

\section{Conclusion}

All four diastereomers of the aldols of tropinone and granatanone with benzaldehyde were characterized as TBDMS ethers. Assignment of the configuration was possible on the basis of comparison of the chemical shifts and coupling constants relevant to the side chain of the TBDMS ethers. The endo isomers could be prepared by equilibration combined with separation on a silica column. The major products of the direct solventless aldol reaction of tropinone and granatanone [20] were assigned the exo,syn configuration on the bases of their NMR data and NMR data of the corresponding TBDMS ethers. The assigned exo,syn configuration of the tropinone aldol was also confirmed by single-crystal diffraction. Derivatization of isomeric tropinone and granatanone aldols as TBDMS ethers combined with their isomerization in the presence of silica can be used for determination of the relative configurations of these types of compounds.

\section{Experimental}

Thin-layer chromatography (TLC) was performed on precoated plates (Merck, silica gel 60, $F_{254}$ ). The spots were detected by using UV light (254 nm) and with phosphomolybdic acid followed by charring. Magnetic resonance spectra $\left({ }^{1} \mathrm{H}\right.$ NMR and ${ }^{13} \mathrm{C}$ NMR) were recorded on a Bruker AVANCE II 400 spectrometer in $\mathrm{CDCl}_{3}$ at ambient temperature. Chemical shifts are reported in parts per million (ppm) downfield of tetramethylsilane. All reagents were purchased from Aldrich. Granatanone was sublimed; benzaldehyde was purified by standard techniques [29]. Dry triethylamine $\left(\mathrm{Et}_{3} \mathrm{~N}\right)$ and dichloromethane (DCM) were distilled from calcium hydride. All air-sensitive reactions were carried out under argon.

Crystallographic data were collected with a Bruker-Nonius Apex-X8 CCD-diffractometer with $\mathrm{Cu} \mathrm{K} \alpha$ radiation $(\lambda=$ $1.54178 \AA$ ) at $296 \mathrm{~K}$. The structure was solved by direct methods and refined by using the SHELXS97 [30] and SHELXL97 [30] programs. All non-H atoms were refined anisotropically; all $\mathrm{H}$ atoms bonded to carbon atoms were placed on geometrically calculated positions and refined by using a riding model. The hydroxy $\mathrm{H}$ atom in the structure was located from $\Delta \rho$ maps and refined isotropically. Crystallographic data (excluding structure factors) for the structure in this paper have been deposited with the Cambridge Crystallographic Data Centre as supplementary publication no. CCDC 887610, for compound exo,syn-3. Copies of the data can be obtained, free of charge, on application to CCDC, 12 Union Road, Cambridge CB2 1EZ, UK, (fax: +44-(0)1223-336033 or e-mail: deposit@ccdc.cam.ac.uk). 
exo, anti-2 - [Hydroxy (phenyl)methyl]-8-methyl-8azabicyclo[3.2.1]octan-3-one (exo,anti-3) [3,4,12] Colorless solid; mp $118-121{ }^{\circ} \mathrm{C}$ (decomp.); ${ }^{1} \mathrm{H}$ NMR $\delta$ 7.32-7.25 (m, $5 \mathrm{H}), 5.23(\mathrm{~d}, J=3.1 \mathrm{~Hz}, 1 \mathrm{H}), 3.61-3.59(\mathrm{~m}, 1 \mathrm{H}), 3.50-3.47(\mathrm{~m}$, $1 \mathrm{H}), 2.86$ (ddd, $J=15.6 \mathrm{~Hz}, 4.6 \mathrm{~Hz}, 1.5 \mathrm{~Hz}, 1 \mathrm{H}), 2.47$ (s, 3H), 2.45-2.42 (m, 1H, eq-H at C-2), 2.33 (dt, $J=15.6 \mathrm{~Hz}, 1.9 \mathrm{~Hz}$, $1 \mathrm{H}), 2.21-2.12(\mathrm{~m}, 1 \mathrm{H}), 1.69-1.53(\mathrm{~m}, 1 \mathrm{H}) ; R_{\mathrm{f}} 0.50(10 \%$ $\mathrm{MeOH} / \mathrm{DCM})$.

exo,syn-2-[Hydroxy (phenyl)methyl]-8-methyl-8azabicyclo[3.2.1]octan-3-one (exo,syn-3) [20] Colorless solid; mp 81-83 ${ }^{\circ} \mathrm{C}$ (decomp.); ${ }^{1} \mathrm{H}$ NMR $\delta$ 7.47-7.22 (m, 5H), 7.35 (br s, $1 \mathrm{H}), 5.01(\mathrm{~d}, J=2.6 \mathrm{~Hz}, 1 \mathrm{H}), 3.51-3.43(\mathrm{~m}, 1 \mathrm{H})$, $3.25-3.18$ (m, 1H), 2.98 (ddd, $J=17.0 \mathrm{~Hz}, 5.2 \mathrm{~Hz}, 1.7 \mathrm{~Hz}, 1 \mathrm{H})$, $2.43(\mathrm{dt}, J=17.0 \mathrm{~Hz}, 1.7 \mathrm{~Hz}, 1 \mathrm{H}), 2.39-2.37$ (m, 1H, eq-H at $\mathrm{C}-2), 2.37$ (s, 3H), 2.20-2.03 (m, 2H), 1.70-1.61 (m, 1H), $1.42-1.35(\mathrm{~m}, 1 \mathrm{H}) ;{ }^{13} \mathrm{C}$ NMR $\delta 210.7,143.7,128.3,126.9$, $125.5,75.7,63.1,61.2,50.3,40.4,26.8,26.4$; HRMS-ESI $(m / z):[\mathrm{M}+\mathrm{Na}]^{+}$calcd for $\mathrm{C}_{15} \mathrm{H}_{19} \mathrm{NO}_{2} \mathrm{Na}, 268.1313$; found, $268.1325 ; R_{\mathrm{f}} 0.40$ (10\% MeOH/DCM, decomp.). The crystal structure has been deposited at the Cambridge Crystallographic Data Centre and allocated the deposition number CCDC 887610; unit-cell parameters: $a=6.1202(1), b=16.9100(3), c=$ 12.6953(2) $\AA, \beta=91.1250(10)$ space group $P 21 / n$.

exo,anti-2-[(tert-Butyldimethylsilyloxy)(phenyl)methyl]-8methyl-8-azabicyclo[3.2.1]octan-3-one (exo,anti-5) [3] The aldol exo,anti-3 (0.982 g, $3.97 \mathrm{mmol})$ was dissolved in dry DCM (11 mL). DMAP (0.057 g, $0.46 \mathrm{mmol})$ and dry $\mathrm{Et}_{3} \mathrm{~N}$ $(5.7 \mathrm{~mL})$ were added, followed by the addition of TBDMSCl $(1.193 \mathrm{~g}, 7.9 \mathrm{mmol})$. The resulting solution was allowed to stand at $\mathrm{rt}$ for $16 \mathrm{~h}$. The reaction mixture was then diluted with $\operatorname{DCM}(5 \mathrm{~mL})$, shaken with $20 \%$ aq $\mathrm{K}_{2} \mathrm{CO}_{3}(10 \mathrm{~mL})$ and extracted with DCM $(3 \times 10 \mathrm{~mL})$. The combined organic extracts were dried $\left(\mathrm{Na}_{2} \mathrm{SO}_{4}\right)$, the solvent was removed under vacuum, and the residue was subjected to flash chromatography in hexanes/AcOEt (1:9), which gave the pure product as a colorless oil $(1.283 \mathrm{~g}, 89 \%) .{ }^{1} \mathrm{H}$ NMR $\delta 7.50-7.20(\mathrm{~m}, 5 \mathrm{H})$, $5.28(\mathrm{~d}, J=9.6 \mathrm{~Hz}, 1 \mathrm{H}), 3.39-3.37(\mathrm{~m}, 1 \mathrm{H}), 2.87-2.82(\mathrm{~m}, 1 \mathrm{H}$, ax-H at C-4), 2.64-2.63 (m, 1H, HC-NMe), 2.36-2.33 (m, 1H, eq-H at C-2), $2.22(\mathrm{~s}, 3 \mathrm{H}), 2.05-1.88(\mathrm{~m}, 3 \mathrm{H}), 1.62-1.53(\mathrm{~m}$, $1 \mathrm{H}), 1.40-1.32(\mathrm{~m}, 1 \mathrm{H}), 0.78(\mathrm{~s}, 3 \mathrm{H}),-0.06(\mathrm{~s}, 3 \mathrm{H}),-0.31(\mathrm{~s}$, $3 \mathrm{H}) ;{ }^{13} \mathrm{C}$ NMR $\delta 209.4,143.3,128.1,127.6,127.1,75.3,68.6$, $63.7,63.0,49.0,41.1,25.71,25.65,25.5,17.9,-4.7,-5.2$.

exo,syn-2-[(tert-Butyldimethylsilyloxy)(phenyl)methyl]-8methyl-8-azabicyclo[3.2.1]octan-3-one (exo,syn-5) Product exo,syn-5 was obtained as a yellow oil $(0.390 \mathrm{~g}, 94 \%)$ in the same way as exo,anti-5 by using exo,syn-3 (0.283 g, $1.15 \mathrm{mmol})$, dry DCM (3.3 mL), DMAP (0.016 g, $0.13 \mathrm{mmol})$, dry $\mathrm{Et}_{3} \mathrm{~N}(1.6 \mathrm{~mL})$, and TBDMSCl $(0.344 \mathrm{~g}, 2.28 \mathrm{mmol})$.
Attempted flash chromatographic purification on silica led to significant isomerization. ${ }^{1} \mathrm{H}$ NMR $\delta 7.38-7.16(\mathrm{~m}, 5 \mathrm{H}), 5.24$ (d, $J=9.3 \mathrm{~Hz}, 1 \mathrm{H}), 3.68-3.62(\mathrm{~m}, 1 \mathrm{H}), 3.42-3.35(\mathrm{~m}, 1 \mathrm{H}), 2.57$ (ddd, $J=14.7 \mathrm{~Hz}, 4.4 \mathrm{~Hz}, 1.9 \mathrm{~Hz}, 1 \mathrm{H}), 2.45$ (dt, $J=9.3 \mathrm{~Hz}$, $1.9 \mathrm{~Hz}, 1 \mathrm{H}$, eq-H at C-2), $2.41(\mathrm{~s}, 3 \mathrm{H}), 2.25-2.05(\mathrm{~m}, 3 \mathrm{H})$, $1.60-1.48(\mathrm{~m}, 2 \mathrm{H}), 0.87(\mathrm{~s}, 9 \mathrm{H}), 0.10(\mathrm{~s}, 3 \mathrm{H}),-0.26(\mathrm{~s}, 3 \mathrm{H})$; ${ }^{13} \mathrm{C}$ NMR $\delta$ 209.2, 142.5, 128.1, 127.7, 126.5, 74.1, 69.7, 63.3, 62.9, 50.7, 41.3, 18.1, 26.0, 25.8, 25.8, -4.51, -4.96; HRMS-ESI $(m / z):[\mathrm{M}+\mathrm{Na}]^{+}$calcd for $\mathrm{C}_{21} \mathrm{H}_{33} \mathrm{NO}_{2} \mathrm{SiNa}$, 382.2178; found, 382.2161; $R_{\mathrm{f}} 0.75$ (40\% AcOEt/hexanes).

endo,syn-2-[(tert-Butyldimethylsilyloxy)(phenyl)methyl]-8methyl-8-azabicyclo[3.2.1]octan-3-one (endo,syn-5) [3] The TBDMS-ether exo,anti-5 $(0.179 \mathrm{~g}, 0.50 \mathrm{mmol})$ was applied on a flash silica column in hexanes/AcOEt (9:1) and left for $18 \mathrm{~h}$. The column was washed with hexanes/AcOEt $(1: 1)$ to remove the starting material $(0.030 \mathrm{~g}, 16 \%)$ and with $\mathrm{MeOH} / \mathrm{DCM}(1: 9)$ to remove the product of isomerization as an oil $(0.141 \mathrm{~g}, 79 \%)$. ${ }^{1} \mathrm{H}$ NMR $\delta 7.39-7.21(\mathrm{~m}, 5 \mathrm{H}), 5.10(\mathrm{~d}, J=7.3 \mathrm{~Hz}), 3.74-3.71$ $(\mathrm{m}, 1 \mathrm{H}), 3.48-3.38(\mathrm{~m}, 1 \mathrm{H}, H \mathrm{C}-\mathrm{NMe}), 3.04-2.96(\mathrm{~m}, 1 \mathrm{H}$, ax-H at C-2), 2.68-2.58 (m, 1H, ax-H at C-4), $2.48(\mathrm{~s}, 3 \mathrm{H})$, $2.12-1.93(\mathrm{~m}, 4 \mathrm{H}), 1.63-1.54(\mathrm{~m}, 1 \mathrm{H}), 0.85(\mathrm{~s}, 9 \mathrm{H}), 0.04(\mathrm{~s}$, $3 \mathrm{H}),-0.31(\mathrm{~s}, 3 \mathrm{H}) ;{ }^{13} \mathrm{C}$ NMR $\delta 208.1,144.4,127.8,127.3$, 127.0, 71.3, 63.0, 62.0, 61.4, 47.7, 38.0, 27.7, 25.8, 25.6, 24.4, $18.0,-4.6,-5.3$.

endo,anti-2-[(tert-Butyldimethylsilyloxy)(phenyl)methyl]-8methyl-8-azabicyclo[3.2.1]octan-3-one (endo,anti-5) The TBDMS-ether exo,syn-5 (0.140 g, $0.39 \mathrm{mmol})$ was applied on a flash silica column in hexanes/AcOEt (9:1). The column was washed with hexanes/AcOEt (1:1) to remove the starting material $(0.028 \mathrm{~g}, 20 \%)$ and with $\mathrm{MeOH} / \mathrm{DCM}(1: 9)$ to remove the product of isomerization as a colorless oil $(0.082 \mathrm{~g}, 59 \%)$. ${ }^{1} \mathrm{H}$ NMR $\delta 7.26-7.19(\mathrm{~m}, 5 \mathrm{H}), 5.01(\mathrm{~d}, J=7.6 \mathrm{~Hz}, 1 \mathrm{H})$, $3.43-3.37(\mathrm{~m}, 1 \mathrm{H}), 3.06$ (ddd, $J=7.6 \mathrm{~Hz}, 1.5 \mathrm{~Hz}, 1.5 \mathrm{~Hz}, 1 \mathrm{H}$ ax-H at C-2), 2.80-2.74 (m, 2H), 2.40 (s, 3H), 2.14 (dd, $J=$ $13.9 \mathrm{~Hz}, 2.4 \mathrm{~Hz}, 1 \mathrm{H}), 1.95-1.85(\mathrm{~m}, 1 \mathrm{H}), 1.65-1.46(\mathrm{~m}, 2 \mathrm{H})$ $1.38-1.28(\mathrm{~m}, 1 \mathrm{H}), 0.78(\mathrm{~s}, 9 \mathrm{H}), 0.09(\mathrm{~s}, 3 \mathrm{H}),-0.16(\mathrm{~s}, 3 \mathrm{H})$; ${ }^{13} \mathrm{C}$ NMR $\delta 207.8,142.5,128.2,127.7,127.0,71.6,63.6$, $62.4,61.5,47.2,37.0,27.7,25.7,24.7,18.1,-4.83,-4.90$; HRMS-ESI $(\mathrm{m} / \mathrm{z}):[\mathrm{M}+\mathrm{Na}]^{+}$calcd for $\mathrm{C}_{21} \mathrm{H}_{33} \mathrm{NO}_{2} \mathrm{SiNa}$, 382.2178; found, 382.2191; $R_{\mathrm{f}} 0.25$ (40\% AcOEt/hexanes).

\section{Supporting Information}

\section{Supporting Information File 1}

Experimental procedures for the preparation and characterization of the remaining compounds. [http://www.beilstein-journals.org/bjoc/content/ supplementary/1860-5397-8-216-S1.pdf] 


\section{Acknowledgements}

The authors are grateful to the University of Bialystok (BST125) and National Science Center, Poland (grant N N204 546939) for financial support.

\section{References}

1. Pollini, G. P.; Benetti, S.; De Risi, C.; Zanirato, V. Chem. Rev. 2006, 106, 2434-2454. doi:10.1021/cr050995+

2. Lee, J. C.; Lee, K.; Cha, J. K. J. Org. Chem. 2000, 65, 4773-4775. doi:10.1021/jo000348c

3. Majewski, M.; Lazny, R. J. Org. Chem. 1995, 60, 5825-5830. doi:10.1021/jo00123a018

4. Sienkiewicz, M.; Wilkaniec, U.; Lazny, R. Tetrahedron Lett. 2009, 50, 7196-7198. doi:10.1016/j.tetlet.2009.10.045

5. Lazny, R.; Sienkiewicz, M.; Olenski, T.; Urbanczyk-Lipkowska, Z.; Kalicki, P. Tetrahedron 2012, 68, 8236-8244. doi:10.1016/j.tet.2012.07.061

6. Lazny, R.; Nodzewska, A. Tetrahedron Lett. 2003, 44, 2441-2444. doi:10.1016/S0040-4039(03)00345-9

7. Lazny, R.; Nodzewska, A.; Sienkiewicz, M. Lett. Org. Chem. 2010, 7, 21-26. doi:10.2174/157017810790533887

8. Lazny, R.; Sienkiewicz, M.; Bräse, S. Tetrahedron 2001, 57, 5825-5832. doi:10.1016/S0040-4020(01)00495-1

9. Brzezinski, K.; Lazny, R.; Sienkiewicz, M.; Wojtulewski, S.; Dauter, Z. Acta Crystallogr., Sect. E 2012, E68, 0149-0150. doi:10.1107/S1600536811053190

10. O'Brien, P. J. Chem. Soc., Perkin Trans. 1 1998, 1439-1458. doi:10.1039/A705961E

11. Simpkins, N. S.; Weller, M. D. Asymmetric Deprotonations Using Chiral Lithium Amide Bases.. In Stereochemical Aspects of Organolithium Compounds; Gawley, R. E., Ed.; Topics in Stereochemistry, Vol. 26; Verlag Helvetica Chimica Acta: Zürich, Switzerland, 2010.

12. Majewski, M.; Zheng, G.-Z. Can. J. Chem. 1992, 70, 2618-2626. doi:10.1139/v92-330

13. Majewski, M.; Ulaczyk, A.; Wang, F. Tetrahedron Lett. 1999, 40, 8755-8758. doi:10.1016/S0040-4039(99)01882-1

14. Majewski, M.; Ulaczyk-Lesanko, A.; Wang, F. Can. J. Chem. 2006, 84, 257-268. doi:10.1139/v06-006

15. Li, J.; Quail, J. W.; Zheng, G. Z.; Majewski, M. Acta Crystallogr., Sect. C 1993, C49, 1410-1412. doi:10.1107/S0108270192013581

16. Lazny, R.; Wolosewicz, K.; Dauter, Z.; Brzezinski, K. Acta Crystallogr., Sect. E 2012, E68, o1367. doi:10.1107/S1600536812014754

17. Lazny, R.; Wolosewicz, K.; Zielinska, P.; Urbanczyk-Lipkowska, Z.; Kalicki, P. Tetrahedron 2011, 67, 9433-9439. doi:10.1016/j.tet.2011.09.096

18. Lazny, R.; Wilkaniec, U. A method for synthesis of tropinone aldols. Polish patent application P388528, Jan 17, 2011.

19. Lazny, R.; Nodzewska, A.; Tomczuk, I. A method for synthesis of a diastereomer of tropinone aldol. Polish patent application P391336, Dec 5, 2011.

20. Lazny, R.; Nodzewska, A.; Tomczuk, I. Tetrahedron Lett. 2011, 52, 5680-5683. doi:10.1016/j.tetlet.2011.08.107

21. Lazny, R.; Ratkiewicz, A.; Nodzewska, A.; Wysocka, J. Tetrahedron Lett. 2012, 53, 5871-5874. doi:10.1016/j.tetlet.2012.08.070

22. Majewski, M.; Zheng, G.-Z. Synlett 1991, 173-175. doi:10.1055/s-1991-20667
23. Heathcock, C. H.; Buse, C. T.; Kleschick, W. A.; Pirrung, M. C.; Sohn, J. E.; Lampe, J. J. Org. Chem. 1980, 45, 1066-1081. doi:10.1021/jo01294a030

24. Heathcock, C. H. The aldol reaction: Acid and general base catalysis In Comprehensive Organic Synthesis; Trost, B. M.; Fleming, I., Eds.; Pergamon: Oxford, 1991; Vol. 2, pp 133-179. doi:10.1016/B978-0-08-052349-1.00027-5

25. Kashrnan, Y.; Cherkez, S. Tetrahedron 1972, 28, 155-165. doi:10.1016/0040-4020(72)80064-4

26. Karplus, M. J. Chem. Phys. 1959, 30, 11-15. doi:10.1063/1.1729860

27. Karplus, M. J. Am. Chem. Soc. 1963, 85, 2870-2871. doi:10.1021/ja00901a059

28. Bifulco, G.; Dambruoso, P.; Gomez-Paloma, L.; Riccio, R. Chem. Rev. 2007, 107, 3744-3779. doi:10.1021/cr030733c

29. Armarego, W. L. F.; Chai, C. L. L. Purification of Laboratory Chemicals, 6th ed.; Elsevier: Burlington, 2009; p 235.

30. Sheldrick, G. M. Acta Crystallogr., Sect. A 2008, A64, 112-122. doi:10.1107/S0108767307043930

\section{License and Terms}

This is an Open Access article under the terms of the Creative Commons Attribution License (http://creativecommons.org/licenses/by/2.0), which permits unrestricted use, distribution, and reproduction in any medium, provided the original work is properly cited.

The license is subject to the Beilstein Journal of Organic Chemistry terms and conditions:

(http://www.beilstein-journals.org/bjoc)

The definitive version of this article is the electronic one which can be found at: doi: $10.3762 /$ bjoc. 8.216 